\title{
Analysis of taste function in patients before and after cochlear implant surgery*
}

\author{
U. Walliczek-Dworschak' ${ }^{1,2}$, C.M. Knauer' ${ }^{1}$, D. Mürbe ${ }^{3}$, A. Mainka³ ${ }^{3}$ T. Hummel ${ }^{1}$ \\ ' Smell and Taste Clinic, Department of Otorhinolaryngology, Technische Universität Dresden, Dresden, Germany \\ 2 Department of Otorhinolaryngology-Head and Neck Surgery, University Hospital of Marburg, University of Giessen \\ and Marburg, Germany \\ ${ }^{3}$ Saxonian Cochlear Implant Center/Division of Phoniatrics and Audiology, Department of Otorhinolaryngology, \\ Technische Universität Dresden, Dresden, Germany
}

Rhinology 56; 2: 149-154, 2018

https://doi.org/10.4193/Rhin17.178

*Received for publication:

August 5, 2017

Accepted: December 2, 2017

\begin{abstract}
Background: Cochlear implantation $(\mathrm{Cl})$, the standard therapy for rehabilitation of severe to profound sensorineural hearing loss, exhibits taste dysfunction as a possible postoperative complication. This study aimed to investigate possible postoperative changes in taste and in addition baseline taste function in $\mathrm{Cl}$ candidates.
\end{abstract}

Methodology: We included 61 patients ( 32 male, 29 female) planned to undergo $\mathrm{Cl}$ surgery and 23 healthy controls ( 8 male, 15 female). Gustatory function was measured using a chemosensory "quasi-threshold" test ("taste strips") and electrogustometry (EGM). To exclude possible effects of olfaction on taste, olfactory function was tested by means of the Sniffin' Sticks' odor identification test. Furthermore, the density of fungiform papillae (fPAP) was analyzed. Measurements were taken pre- and 2-4 weeks postoperative.

Results: Preoperative taste function and fPAP density was reduced in Cl patients compared to controls. The fPAP density correlated significantly with the total taste score, EGM scores and age. Postoperative taste function decreased significantly, whereas EGM scores and fPAP density did not significantly change. Also baseline olfactory function in $\mathrm{Cl}$ candidates was decreased, whereas no significant change of olfactory function was found post-surgery.

Conclusion: $\mathrm{Cl}$ candidates exhibited taste and olfactory dysfunction already preoperatively. Furthermore, a significant decrease in taste scores after $\mathrm{Cl}$ surgery was detected.

Key words: taste, gustatory function, cochlear implant surgery, olfaction, taste papillae

\section{Introduction}

Taste sensitivity of the anterior two thirds of the tongue is mediated by the chorda tympani, which arises from the facial neve. The chorda tympani travels through the middle ear between the long crus of the incus and the manubrium mallei, close to the upper part of the tympanic membrane ${ }^{(1)}$. Research has shown, that surgery involving middle ear structures bears the risk of damaging the chorda tympani and, consequently, to distortions of gustatory function ${ }^{(2-5)}$. A common ear surgery, in which structures of the middle and inner ear are at risk of being injured, is $\mathrm{Cl}$ surgery, which has become the method of choice for the therapy of patients suffering from severe to profound sensorineural hearing loss who do not benefit from conventional hearing aids.
However, only limited information is available about possible taste dysfunctions in $\mathrm{Cl}$ candidates ${ }^{(6-10)}$.

Most studies investigated possible influences on taste function by means of ratings/questionnaires, which are difficult to interpret ${ }^{(11)}$. Limited research is available providing objective information about the gustatory function of $\mathrm{Cl}$ patients measured with validated methods ${ }^{(8,10)}$. Mueller et al. studied gustatory function of $\mathrm{Cl}$ candidates using the validated "taste strips", demonstrating that taste function decreased slightly after surgery, whereas ratings of gustatory function remained stable ${ }^{(10)}$. Similarly, Jeppesen et al. did not find any significant decrease in taste function ${ }^{(8)}$. Information about the frequency of the occurrence of taste disturbances after $\mathrm{Cl}$ surgery is of 
special interest in order to preoperatively inform patients about the potential risk of surgery. An intact taste function is especially important for the enjoyment of food ${ }^{(12)}$ and gustatory dysfunctions may lead to changes in dietary habits, weight loss, depression, and, hence, to a reduced quality of life ${ }^{(13)}$. The aim of the present study was therefore not only to investigate classic taste function parameters by means of the lateralized taste strips and electrogustometry (EGM) but also the density of taste papillae of $\mathrm{Cl}$ candidates and its possible changes after surgery.

\section{Materials and methods}

After the approval of the local ethics committee (number EK 395102014), the present prospective study was performed from October 2014 to August 2016 in the Smell and Taste Clinic at the Department of Otorhinolaryngology-Head and Neck Surgery, "Technische Universität" Dresden in cooperation with the Saxonian $\mathrm{Cl}$ center. This work has been conducted according to the Declaration of Helsinki on biomedical research involving human subjects. After providing detailed information to the patients about potential benefits and risks of the study written consent was obtained.

\section{Patients}

The study involved 61 patients ( 32 male, 29 female) who were planned to undergo unilateral $\mathrm{Cl}$ surgery (right ear $\mathrm{n}=30$; left ear $\mathrm{n}=31$ ) and a group of 23 healthy controls ( 8 male, 15 female). Prior to inclusion in this study all participants underwent a thorough ear, nose, and throat examination to rule out pathologies of the middle ear and oral cavity, which might affect taste function. Subjects with pre-existing gustatory dysfunctions and pathologies known to affect gustatory function were excluded from the study (e.g., neurologic/psychiatric diseases: Parkinson's disease, depression, dementia; endocrine diseases: e.g., hypothyreosis, diabetes mellitus; renal insufficiency, acute or chronic diseases of the oropharynx: carcinoma, inflammations; pregnancy).

\section{Assessment of function}

Because taste perception is influenced by smell ${ }^{(14)}$, olfactory function was screened using the odor identification part of the validated "Sniffin' Sticks" (15,16) (Burghart GmbH, Wedel, Germany) to ascertain that changes in gustatory function were not caused by olfactory impairment. All measurements were taken prior to and approximately four weeks after surgery in patients, respectively, and in healthy controls also two times with an interval of two to four weeks. All participants presented at the follow up. Participants were asked not to smoke, eat, or drink anything other than water for one hour prior to all measurements to avoid chemosensory desensitization.

Assessment of orthonasal olfactory function

Olfactory function was screened using the 16-item odor identi- fication (ID) part of the Sniffin' Sticks. Here 16 different familiar odors are presented using felt-tip pen-like dispensers. For odor presentation, the pen's cap is removed and the felt tip is positioned approximately $2 \mathrm{~cm}$ in front of the participant's nostrils for $3 \mathrm{sec}$. The participant's task is to identify the correct odor from a list of 4 verbal descriptors in a forced choice paradigm. The number of correctly identified odors is recorded with a total score ranging from 0 to 16 points. Normative data for this test are available ${ }^{(17)}$. The tenth percentile of scores taken from young, healthy subjects differentiates normosmic people from those with impaired olfactory function ${ }^{(17)}$. When a patient scored below this value, he or she was considered hyposmic and excluded from this study.

\section{Assessment of taste function \\ Taste strips}

Gustatory function was assessed in a lateralized way with the validated "taste strips" ${ }^{(18,19)}$. This test is based on spoon shaped filter papers which are impregnated with 4 different concentrations of the four taste qualities (sweet: $0.4,0.2,0.1,0.05 \mathrm{~g} / \mathrm{ml}$ sucrose; sour: $0.3,0.165,0.09,0.05 \mathrm{~g} / \mathrm{ml}$ citric acid; salty: $0.25,0.1$, $0.04,0.016 \mathrm{~g} / \mathrm{ml}$ sodium chloride; bitter: $0.006,0.0024,0.0009$, $0.0004 \mathrm{~g} / \mathrm{ml}$ quinine hydrochloride). The taste strips were presented in increasing concentrations in a randomized order and placed alternatingly on the left or right side of the protruded anterior tongue, respectively. Participants were asked to identify the presented taste stimulus from a list (sweet, sour, salty and bitter) within a forced choice paradigm (4-alternative forced choice). After each presentation of a taste stimulus participants rinsed their mouth with tap water. Maximum score for each side of the tongue was 16 points, resulting in a maximum sum = total taste score of 32 points.

Taste scores for each participant were compared at each testing session to sex and age-related normative values ${ }^{(19)}$. The tenth percentile of the distribution of taste scores in young, healthy people divided normogeusia from a reduced taste function. We arbitrarily assumed a clinical relevant change of taste function to be $>6$ points difference compared to baseline measurements.

\section{Electrogustometry}

The threshold for an electrically induced taste stimulus was assessed by means of an electrogustometer (TR-06, RION, Tokyo, Japan). The application of the stimulus was performed using a monopolar electrode, which was positioned on the tongue tip (innervated by the chorda tympani of the facial nerve) and at the area of the vallate papillae on both sides of the tongue (innervated by the glossopharyngeal nerve). Four regions of the tongue (anterior right/left; posterior right/left) were measured by means of this method. The strength of stimulation (stimulus duration $500 \mathrm{~ms}$ ) ranged from -6 gustatory decibels $(\mathrm{dBg})(4 \mathrm{~mA})$ up to 34 
Table 1. Comparison of preoperative against postoperative scores in $\mathrm{Cl}$ patients. Total taste score represents the sum of the taste strip score of the right and left tongue side. EGM score is also combined for the right and left tongue side.

\begin{tabular}{|lccc|}
\hline & $\begin{array}{c}\text { Preoperative } \\
\text { Mean value }\end{array}$ SD & $\begin{array}{c}\text { Postoperative } \\
\text { Mean value } \pm \text { SD }\end{array}$ & p value \\
\hline Total taste score & $19.73 \pm 5.9$ & $18.56 \pm 6.01$ & 0.023 \\
\hline EGM & $15.68 \pm 9.7$ & $15.70 \pm 9.3$ & 0.387 \\
$\begin{array}{l}\text { Number of Taste } \\
\text { papillae }\end{array}$ & $14.35 \pm 7.67$ & $14.74 \pm 7.8$ & 0.697 \\
\hline Odor ID & $11.46 \pm 2.84$ & $11.82 \pm 2.81$ & 0.862 \\
\hline
\end{tabular}

dBg (400 mA). A 2-AFC paradigm (perception of the stimulus, yes or no) was performed with increasing intensities within a staircase paradigm ${ }^{(20)}$. Two correct or one incorrect answers led to a decrease or increase of stimulus intensity, the so-called turning point. The threshold was estimated as the mean of the last four turning points. According to the German Society for Olfactology and Gustology, threshold score differences greater than $7 \mathrm{dBg}$ between the left and right side of the tongue were considered pathologic (21).

\section{Quantification of the fungiform papillae (fPap)} Indigotin (E132) mixed with water (ratio 1:5) was used to stain epithelia and taste pores (Indigotin, Wusitta food coloring, Sitzendorf, Germany) on the side of the tongue corresponding to the side of the operated ear. A filter paper strip delineating a tongue area of $0.79 \mathrm{~cm}^{2}$ was placed of the tongue tip for quantification of fungiform papillae (fPap). With the subject's mouth open and tongue extended, images were taken (Sony DSC W170, Tokyo, Japan). Analysis was performed according to the "Denver Papillae Protocol for Objective Analysis of Fungiform Papillae" (22). fPap were identified on the basis of their form, size, color and elevation and were measured with the help of the program "Image J". Morphologic examination and quantification of fPap were performed in an unblinded fashion.

\section{Cl-Surgery}

The surgical procedure consisted of a regular mastoidectomy with posterior tympanotomy, followed by a round window insertion of the $\mathrm{Cl}$ electrode or an anterior approach.

Chorda injuries were recorded and also signs of possible chorda injuries were recorded. As only in 4 patients, chorda injuries were recorded, and there were only in 2 patients signs of chorda injuries. Hence, because of the small sample size statistical evaluation of this subgroup of patients was not reasonable and was not performed. We provided information about these patients in Table 4.
Table 2. Comparison of fPAP density between healthy control group and patients EGM scores were combined for both tongue sides

\begin{tabular}{|c|c|c|c|}
\hline & $\begin{array}{c}\text { Patients } \\
\text { Mean value } \pm S D\end{array}$ & $\begin{array}{l}\text { Control Group } \\
\quad(n=23) \\
\text { Mean value } \pm S D\end{array}$ & p value \\
\hline $\begin{array}{l}\text { Total taste score both } \\
\text { sides preoperative }\end{array}$ & $18.7 \pm 5.8$ & $22.5 \pm 5.2$ & 0.008 \\
\hline $\begin{array}{l}\text { Total taste score both } \\
\text { sides postoperative }\end{array}$ & $17.1 \pm 5.9$ & $22.5 \pm 4.5$ & 0.001 \\
\hline $\begin{array}{l}\text { EGM preoperative } \\
\text { (in } \mathrm{dB} \text { ) }\end{array}$ & $17.8 \pm 9.5$ & $10.6 \pm 8.3$ & 0.002 \\
\hline $\begin{array}{l}\text { EGM postoperative } \\
\text { (in } \mathrm{dB} \text { ) }\end{array}$ & $18.0 \pm 8.4$ & $9.8 \pm 9.0$ & 0.001 \\
\hline $\begin{array}{l}\text { Number of Taste } \\
\text { papillae preoperative }\end{array}$ & $12.51 \pm 6.44$ & $19.22 \pm 8.62$ & 0.002 \\
\hline $\begin{array}{l}\text { Number of Taste } \\
\text { papillae postoperative }\end{array}$ & $12.84 \pm 8.75$ & $19.78 \pm 8.75$ & $<0.001$ \\
\hline
\end{tabular}

\section{Statistical analysis}

All statistical analyses were conducted with the software SPSS vs. 21 (SPSS Inc., Chicago, IL, USA). The number of patients was determined based on a sample size estimate. To compare chemosensory parameters before surgery with values from a healthy control population t-tests for independent variables were used. The relations of the different gustatory measures (total taste score, EMG scores, density of fPAP) among each other and with age was analyzed using Pearson correlations. Significance level was set at $\mathrm{p}<0.05$.

\section{Results}

Participants were 61 patients ( 32 male, 29 female; mean age \pm SD, $59 \pm 16$ years) planned to undergo unilateral $\mathrm{Cl}$ surgery (right ear $n=30$; left ear $n=31$ ) and a group of 23 healthy controls ( 8 male, 15 female; mean age $55 \pm 22$ years).

\section{Olfactory function}

The baseline odor identification score of patients was, on average $11.1 \pm 2.9$ and $11.4 \pm 2.9$ after surgery. The healthy control group obtained significantly better results (12.5 \pm 2.5 (first testing session; $\mathrm{p}=0.036$ ) versus $12.8 \pm 2.2$ (second testing session; $p=0.043$ ) compared to patients. Olfactory function did not change postoperatively compared to baseline $(p=0.86)$ (Table 1$)$.

\section{Gustatory function}

Taste score values (total taste score, EMG score) and fPAP density in patients differed significantly from the control group (see Table 2). According to the total taste score 1953 patients (87\%) were normogeusic prior to surgery and 8 patients (13\%) already showed an impaired taste function. After $\mathrm{Cl}$ surgery taste function remained clinically stable in 54 patients (88.5\%) (no change of total taste score by more than 6 points), total taste score of 
Table 3. Side different results of taste function of $\mathrm{Cl}$ patients.

\begin{tabular}{|c|c|c|c|c|c|c|}
\hline & \multicolumn{3}{|c|}{ Cl surgery left side } & \multicolumn{3}{|c|}{ Cl surgery right side } \\
\hline & $\begin{array}{l}\text { Summed taste } \\
\quad \text { score } \\
\text { Left tongue Side } \\
\text { Mean value } \pm \text { SD }\end{array}$ & $\begin{array}{l}\text { Summed taste } \\
\text { score } \\
\text { Rright tongue side } \\
\text { Mean value } \pm \text { SD }\end{array}$ & P value & $\begin{array}{l}\text { Summed taste } \\
\text { score } \\
\text { Left tongue Side } \\
\text { Mean value } \pm \text { SD }\end{array}$ & $\begin{array}{l}\text { Summed taste } \\
\text { score } \\
\text { Right tongue side } \\
\text { Mean value } \pm \text { SD }\end{array}$ & P value \\
\hline preoperative & 8.81 & 9.55 & 0.003 & 9.27 & 9.77 & $<0.001$ \\
\hline postoperative & 8.23 & 9.16 & 0.005 & 8.43 & 8.33 & 0.001 \\
\hline
\end{tabular}

Table 4. Taste function of patients, whose chorda tympani has been injured or seemed to have been injured during $\mathrm{Cl}$ surgery.

\begin{tabular}{|c|c|c|c|c|c|c|c|}
\hline Patient & $\begin{array}{c}\text { Taste strip } \\
\text { score oper- } \\
\text { ated side preop } \\
\text { Mean value } \pm \text { SD }\end{array}$ & $\begin{array}{c}\text { Taste strip } \\
\text { score non- } \\
\text { operated side } \\
\text { preop } \\
\text { Mean value } \pm \text { SD }\end{array}$ & $\begin{array}{c}\text { Taste strip } \\
\text { score operated } \\
\text { side Postop } \\
\text { Mean value } \pm \text { SD }\end{array}$ & $\begin{array}{c}\text { Taste strip } \\
\text { score non- } \\
\text { operated side } \\
\text { postop } \\
\text { Mean value } \pm \text { SD }\end{array}$ & $\begin{array}{c}\text { Density of fPAP } \\
\text { preop } \\
\text { Mean value } \pm \text { SD }\end{array}$ & $\begin{array}{c}\text { Density of fPAP } \\
\text { postop } \\
\text { Mean value } \pm S D\end{array}$ & Chorda tympani \\
\hline 1 & 10 & 5 & 8 & 4 & 9 & 11 & injured \\
\hline 2 & 10 & 7 & 7 & 5 & 5 & 6 & injured \\
\hline 3 & 5 & 10 & 2 & 8 & 14 & 7 & injured \\
\hline 4 & 4 & 4 & 4 & 4 & 0 & 0 & injured \\
\hline 5 & 5 & 12 & 7 & 10 & 7 & 4 & Indication for injury \\
\hline 6 & 5 & 4 & 3 & 7 & 20 & 18 & Indication for injury \\
\hline
\end{tabular}

1 patient (1.6\%) improved more than 6 points and 6 patients $(9.8 \%)$ showed a clinically decrease in total taste score by more than 6 points. Statistical analysis showed that the total taste score was significantly decreased (change of more than 1 point in total taste score) post-surgery $(p=0.023)$, whereas EMG scores and fPAP density did not significantly change (Table 1 ).

Interestingly, the total taste strip score did not differ significantly between the tongue side corresponding to ear surgery and the tongue side corresponding to the non-operated ear neither preoperatively ( $p=0.74)$ nor postoperatively $(p=0.21)$. In addition, total taste scores also decreased on the non-operated ear side (Table 3). EGM scores were significantly higher on the operated tongue side, compared to the side which has not been operated (preoperatively: $p=0.001$; postoperatively $p=0.001$ ). This was true for the anterior tongue part (innervated by: CTN) (preoperatively: $p=0.001$; postoperatively $p=0.001$ ) and for the posterior tongue part (innervated by: N. glossopharyngeus) $(p=0.009)$ for both pre- and postoperative.

The total taste score correlated significantly with the density of fPAP (preoperative $(r=0.48, p=0.001)$; postoperative $(r=0.33$, $\mathrm{p}=0.009)$ ). Also the EGM score(left+right side) correlated significantly with the number of taste papillae (preoperative: $r=-0.48, p<0.001$; postoperative: $r=-0.29, p=0.030$ ). The density of fPAP correlated significantly with the age of participants (preoperative: $r=-0.39, p=0.012$; postoperative: $r=-0.28, p=0.027$ ).

\section{Discussion}

This study demonstrated that $\mathrm{Cl}$ candidates exhibit reduced taste sensitivity; $13 \%$ of the patients showed an impaired baseline taste function, which is in line with the literature, where approximately $17-20 \%$ of the population are affected by hypogeusia ${ }^{(7,9,23)}$. Interestingly, patients showed lower taste scores compared to our control group. However, these results are in contrast to other research, which reported a lower percentage (5\%) of $\mathrm{Cl}$ candidates affected by taste disturbances ${ }^{(6)}$. Most of existing studies concerning taste in $\mathrm{Cl}$ surgery collected retrospective data or data from subjective ratings via questionnaires ${ }^{(7,9,24)}$. The present study used not only the validated taste strips, which allow lateralized gustatory testing, but also EGM for the taste investigation. Furthermore the density of taste papillae was analyzed. It could be shown that baseline taste function of $\mathrm{Cl}$ candidates was reduced compared to a healthy control group ( $18.69 \pm 5.84$ vs. $22.48 \pm 5.22 ; p=0.008)$. These findings could be underlined by EGM scores ( $17.77 \pm 9.50$ vs. $10.59 \pm 8.33$; $\mathrm{p}=0.002$ ) and a lower fPAP density in $\mathrm{Cl}$ candidates prior to their surgery (12.51 \pm 6.44 vs. $19.22 \pm 8.62 ; p=0.002)$. However, only 6 patients (9.8\%) showed a decrease by 6 points or more, which we assumed to be clinically relevant. Preoperatively all of these 6 patients were normogeusic. In line with our results, Jeppesen et al. reported about a decreased gustatory function preoperatively measured by means of taste strips in the majority of 
13 patients ${ }^{(8)}$. Also Mueller et al. reported in 24 patients about a baseline decreased preoperative taste score ${ }^{(10)}$. The present study showed that the total taste score significantly decreased post-surgery (preoperatively: $18.69 \pm 5.84$, postoperatively 17.08 $\pm 5.87 ; p=0.023$ ), whereas EGM scores and fPAP density did not change. These results are in line with findings of Mueller et al., who analyzed taste function after $\mathrm{Cl}$ surgery by means of the taste strips. They detected a significant reduction in taste function on the operated side of the tongue in $\mathrm{Cl}$ patients 4 days and 18 months after $\mathrm{Cl}$ surgery ${ }^{(10)}$. However, a limitation of the present study is the rather short follow up period of 4 weeks, given that other research showed reduced taste after ear surgery after several months.

In this study, we found, that also the summed taste score of the non-operated ear side decreased postoperatively. We cannot explain this finding, especially because patients did not show any preoperative finding (e.g., there was no chronic otitis present) that could help to explain this fact. However, taste perception is special with respect to psychological projections; for example, most people do not realize that there is no taste on the middle of the tongue because there are no taste receptors. When testing too close to the center of the tongue, areas with a lower density of taste receptors might be involved and, in consequence, false (too low) taste scores may result.

Also Mikkelsen et al. reported about postoperative taste disturbances in $17 \%$ of their patients ${ }^{(9)}$. An even higher percentage of patients (45\%) subjectively exhibiting taste disturbances after $\mathrm{Cl}$ surgery was reported by Lloyd et al. ${ }^{(7)}$. In $19 \%$ of those patients taste distortions remained after the end of the follow up period of 51 months. However, no objective assessment of taste function was performed in these studies.

Other studies reported about a reduced taste at long-term follow-up in up to $5 \%$ of the patients ${ }^{(6,24)}$. In contrast Jeppesen et al. reported no change in taste scores ${ }^{(8)}$.

Interestingly, the total taste strip score was not found to differentiate between the tongue side corresponding to the ear surgery and the side corresponding to the non-operated ear $(p=0.351)$, whereas EGM scores did. We therefore recommend to not only use taste strips for analysis of gustatory function in $\mathrm{Cl}$ surgery, but to also use EGM.

Contrary to our expectations, postoperative EGM scores and fPAP were not found to be significantly different from preoperative findings. Still, there is a possibility that changes in PPAP could have been seen using Laser scanning microscopy volumetry ${ }^{(25)}$, because the time course of volume changes seems to exhibit a better correlation with taste function than morphological changes like papilla density. This could be shown in a case report of a patient suffering from hypogeusia ${ }^{(25)}$. Human taste bud volume seems to change within a 10 week period, with a volume maximum of 3-5 weeks. If possible, future studies should therefore focus on taste bud volume.
Concentrating on the 4 patients with injured chorda tympani, density of taste papillae increased in two patients, remained stable in one patient and decreased in one patient. In the two patients who showed signs of a possible chorda affection density of taste papillae decreased These findings are in contrast to research showing that the density of taste papillae decreases after chorda tympani transection ${ }^{(26)}$. Other research could confirm these findings and showed similar findings after 11 days ${ }^{(27)}$, respectively 3 weeks after nerve transection ${ }^{(28)}$. However, it needs to be kept in mind that with 6 patients a reliable statement is problematic.

In addition to the objective taste measurement also assessment of the patient's ratings would have been useful, although it is important to mention that subjective and objective taste perception may differ significantly ${ }^{(29)}$.

Regarding olfactory function of $\mathrm{Cl}$ candidates, we found significantly reduced olfactory test scores compared to healthy controls. Olfactory function remained stable postoperatively. Considering the comparability of the two groups in terms of age, sex, and previous/current disorders it is difficult to explain these differences between patients and controls.

\section{Conclusion}

$\mathrm{Cl}$ candidates seem to exhibit taste dysfunctions already preoperatively. Furthermore, a significant decrease in taste scores after $\mathrm{Cl}$ surgery was detected, comparable to other ear surgery, where the middle ear is involved. Often these symptoms are transient and recover during the first year after ear surgery ${ }^{(35)}$. Hence, $\mathrm{Cl}$ candidates need to be informed about this possible complication. In addition, preoperative measurement of gustatory function is recommended, especially against the background of possible reduced baseline taste function of $\mathrm{Cl}$ candidates. For analysis of gustatory function in $\mathrm{Cl}$ surgery, it seems to be useful to not only use taste strips, but also EGM.

\section{Acknowledgement}

No funding has been received.

\section{Authorship contribution}

UWD: analysis of results, critical review of all contents, write-up of manuscript; CMK: collection of data, critical review of all contents, write-up of manuscript; DM: concept of study, critical review of all contents, write-up of manuscript; AM: concept of study, analysis of results, critical review of all contents, write-up of manuscript; $\mathrm{TH}$ : concept of study, analysis of results, critical review of all contents, write-up of manuscript.

\section{Conflict of interest}

The authors declare that there are no conflicts of interest regarding the publication of this paper. 


\section{References}

1. Rauchfuss A. Surgical anatomy. In: Hildmann $H$, Sudhoff $H$, eds. Middle ear surgery. Berlin, Germany: Springer; 2006. 1-9 p.

2. SaitoT, ManabeY, ShibamoriY et al. Longterm follow- up results of electrogustometry and subjective taste disorder after middle ear surgery. Laryngoscope. 2001; 111:2064-70.

3. Sone M, Sakagami M, Tsuji K, Mishiro Y. Younger patients have a higher rate of recovery of taste function after middle ear surgery. Arch Otolaryngol Head Neck Surg. 2001; 127:967- 9

4. Just T, Homoth J, Graumuller S, Pau HW. Taste disorders and recovery of the taste function after middle ear surgery [in German]. Laryngorhinootologie. 2003; 82:494-500.

5. Nin T, Sakagami M, Sone-Okunaka M, Muto T, Mishiro Y, Fukazawa K. Taste function after section of chorda tympani nerve in mid dle ear surgery. Auris Nasus Larynx. 2006; 33:13-7.

6. Wagner $\mathrm{JH}$, Basta $\mathrm{D}$, Wagner F, Seidl RO, Ernst A, Todt I. Vestibular and taste disorders after bilateral cochlear implantation. Eur Arch Otorhinolaryngol. 2010; 267:1849-54.

7. Lloyd S, Meerton L, Di Cuffa R, Lavy J, Graham J. Taste change following cochlear implantation. Cochlear Implants Int. 2007; 8:203-10

8. Jeppesen J, Holst R, Faber CE. Changes in salivary secretion and sense of taste following cochlear implantation: a prospective study. Acta Otolaryngol. 2015; 135:578-85

9. Mikkelsen KS, Ovesen T, Swan CZ. Pre- and post-operative dizziness, tinnitus, and taste disturbances among cochlear implant recipients. J Laryngol Otol. 2017; 131:309 315.

10. Mueller CA, Khatib S, Temmel AF, Baumgartner WD, Hummel T. Effects of cochlear implantation on gustatory function. Ann Otol Rhinol Laryngol. 2007; 116:498-501.

11. Soter A, Kim J, Jackman A, Tourbier I, Kaul A, Doty RL. Accuracy of self-report in detecting taste dysfunction. Laryngoscope. 2008; 118:611-7.

12. Small DM, Prescott J. Odor/taste integration and the perception of flavor. Exp Brain Res. 2005; 166:345-57.

13. Mattes RD, Cowart BJ, Schiavo MA et al Dietary evaluation of patients with smell and/or taste disorders. Am J Clin Nutr. 1990; 51:233-40.

14. Landis BN, Scheibe M, Weber C et al. Chemosensory interaction: acquired olfactory impairment is associated with decreased taste function. J Neurol. 2010; 257:1303-8.
15. Kobal G, Hummel T, Sekinger B, Barz S, Roscher S, Wolf S. "Sniffin' Sticks": screening of olfactory performance. Rhinology. 1996; 34:222-6

16. Hummel T, Sekinger B, Wolf SR, Pauli E, Kobal G. "Sniffin Sticks": olfactory performance assessed by the combined testing of odor identification, odor discrimination and olfactory threshold. Chem Senses. 1997; 22:39-52.

17. Hummel T, MackaySim A, Gudziol H, Mackay-Sim A. Normative data for the "Sniffin" Sticks" including tests of odor identification, odor discrimination and olfactory thresholds: an upgrade based on a group of more than 3,000 subjects. Eur Arch ORL. 2007; 264:237-243.

18. Mueller C, Kallert S, Renner B, et al. Quantitative assessment of gustatory function in a clinical context using impregnated "taste strips". Rhinology. 2003; 41:2-6.

19. Landis BN, Welge-Luessen A, Brämerson A et al. "Taste Strips" - a rapid, lateralized, gustatory bedside identification test based on impregnated filter papers. J Neurol. 2009; 256:242-8.

20. Zwisler R. 1998. Psychophysische Me thoden. Psychol. Methodenlehre. URL: http://www.zwisler.de/scripts/methoden/ node4.html

21. Arbeitsgemeinschaft OuG, Schmeck -störungen. 1996. AWMF: Aktuelle Leitlinien, Registriernummer 017-052.

22. Nuessle TM, Garneau NL, Sloan MM Santorico SA. Denver Papillae Protocol for Objective Analysis of Fungiform Papillae. J. Vis. Exp. 2015;e52860.

23. Khil L, Wellmann J, Berger K. Determinants of Single and Multiple Sensory Impairments in an Urban Population. Otolaryngol Head Neck Surg. 2015; 153: 364-71.

24. Hansen S, Anthonsen K, Stangerup SE, Jensen JH, Thomsen J, Caye-Thomasen P. Unexpected findings and surgical complications in 505 consecutive cochlear implantations: a proposal for reporting consensus. Acta Otolaryngol. 2010; 130:540-9.

25. Srur E, Pau HW, Just T. Changes in taste bud volume during taste disturbance. Auris Nasus Larynx 2011: 38:512-5.

26. Just T, Pau HW, Witt M, Hummel T. Contact endoscopic comparison of morphology of human fungiform papillae of healthy subjects and patients with transected chorda tympani nerve. Laryngoscope 2006; 116:1216-22.

27. Nakashima T, Toyoshima K, Shimamura A, Yamada N. Morphological changes of taste buds and fungiform papillae following long-term neurectomy. Brain Res
1990;533:321-323.

28. Oakley B, Lawton A, Riddle DR, Wu LH. Morphometric and immunocytochemical assessment of fungiform taste buds after interruption of the chorda-lingual nerve. Microsc Res Tech 1993:26:187-195.

29. Soter A, Kim J, Jackman A, Tourbier I, Kaul A, Doty RI. Accuracy of self-report in detecting taste dysfunction. Laryngoscope 2008:118:611-617

30. Mackay-Sim A, Johnston AN, Owen C, Burne $\mathrm{TH}$. Olfactory ability in the healthy population: Reassessing presbyosmia. Chem Senses 2006; 31:763-771.

31. Pinto JM, Wroblewski KE, Kern DW, Schumm LP, McClintock MK. Olfactory dysfunction predicts 5-year mortality in older adults. PLoS One 2014; 9:e107541.

32. Aydın E, Tekeli H, Karabacak E, Altunay IK, Aydın Ç, Çerman AA, Altundağ A, Salihoğlu $M$, Çayönü $M$. Olfactory functions in patients with psoriasis vulgaris: correlations with the severity of the disease..Arch Dermatol Res. 2016; 308:409-14

33. Zycinska K, Straburzynski M, Nitsch-Osuch A, Krupa R, Hadzik-Błaszczyk M, Cieplak M, Wardyn K. Prevalence of Olfactory Impairment in Granulomatosis with Polyangiitis. Adv Exp Med Biol. 2016; 878:1-7

34. Walliczek-Dworschak U, Cassel W, Mittendorf $L$, Pellegrino R, Koehler $U$, Güldner C, Dworschak POG, Hildebrandt O, Daniel H, Günzel T, Teymoortash A, Hummel T . Continuous positive air pressure improves orthonasal function of patients with obstructive sleep apnea. Sleep Med 2017: 34:24-29

35. McManus LJ, Stringer MD, Dawes PJ. latrogenic injury of the chorda tympani: a systematic review. J Laryngol Otol 2012; 126:8-14

U. Walliczek-Dworschak, M.D.

Department of Otorhinolaryngology

Head and Neck Surgery

University Hospital of Marburg

University of Giessen and Marburg

Baldingerstraße

35043 Marburg

Germany

Tel: +496421 5866478

E-mail: wallicze@staff.uni-marburg.de 